\title{
Iragi Jourcmal of Nanotechnology
}

syththesis and appplication

\section{Optical and Structural Properties of CdS Quantum Dots Synthesized Using (MW-CBD) Technique}

\author{
Ahmed S. Abed ${ }^{1 *}$, Sattar J. Kasim ${ }^{1}$, Abbas F. Abbas ${ }^{2}$ \\ 1: Physics Department, College of Science, University of Basra, Iraq \\ 2: Chemistry Department, College of Science, University of Basra, Iraq \\ *Corresponding author: Ahmed S. Abed email: ahmedalkhanjjar3@gmail.com
}

\section{Keywords:}

Nanoparticles;

Quantum Dots (QDs);

CdS, MW-CBD method.

\begin{abstract}
In the present study, the microwave heating method has been used to prepare cadmium sulfide quantum dots CdSQDs films. CdS nanoparticles size average obtained as $(7 \mathrm{~nm})$. The morphology, structure and composition of prepared CdSQDs were examined using (FE-SEM), (XRD) and (EDX). Optical properties of CdSQDs thin films formed and deposited onto glass substrates have been studied at room temperature using UV/ Visible spectrophotometer within the wavelength of (300-800nm), and Photoluminescence (PL) spectrum. The optical energy gap (Eg) which estimated using Tauc relation was equal $(2.6 \mathrm{eV})$. Prepared $\mathrm{CdS}$ nanoparticles thin films are free from cracks, pinholes and have high adhesion to substrate.
\end{abstract}

\section{Introduction}

Recently, interest in nanomaterials has increased due to their unique properties in fields different [1]. The fundamental properties of materials such as electrical, optical and magnetic properties, can be controlled using controlling the size of nanomaterials without changing their chemical composition [2]. The importance of semiconductor nanomaterials is connected to industrial research and development, due to its electronic and optical properties dependent on the size of nanomaterials. thus, it is used in different fields [3,4]. In particular, sulfides of transitional metals acquired attention for applications such as sensors, optical filters, solar cells, and photovoltaic systems among others because the optical properties characteristic of the size and morphology of the crystal, essentially characterized by the transition phase from the electrical conductivity [3]. There are different methods for preparing nanomaterials [5-7].

Inorganic nanocomposites such as (CdS, CdSe and CdTe) have many properties such as, can be controlled optical energy gap and high light absorption [8]. The great importance of CdS nanoparticles due to has properties and its high absorption in the visible region, so many methods were used to prepare, such as (CBD), (MW-CBD), (SILAR) [9-12]. Because of CdS properties, widely used in different applications [13]. It is one of the most studied materials with a direct bandgap of $2.42 \mathrm{eV}$ [14]. CdS nanoparticles have been studied due to its potential technological applications in field-effect transistors, solar cells [15], light-emitting diodes, photocatalysis, fluorescence probe [16], infrared photodetector, environmental sensors and biological sensors [5]. The study of optical and electrical properties CdS quantum dots has become of great importance to more researchers. [17]. By defining and controlling the methods and variables can be the preparation of CdS nanoparticles is high-quality [18]. There are many techniques to prepare CdS quantum dots, but they 
are costly, at high temperatures and requires long preparation time, making those methods either expensive, explosive, moisture sensitive, extremely toxic, and energy-consuming [19,20].

The use of (MW-CBD) technique in preparing nanomaterials showed very rapid growth due to the homogeneous molecular thermal reaction [21]. The size and structure of prepared nanomaterials can be influence by the solvent at using (MW-CBD) technique [22]. Because of polarity has water, it is considered one of the best solvents used in the (MWCBD) technique [23]. Therefore, due to (MW-CBD) technique properties are widely used in the preparation of nanomaterial.

In the present paper, CdS nanoparticles are deposited using (MW-CBD). The structural, morphological, and optical properties of CdS nanoparticles have been charactered and studied.

\section{Experimental Work}

Quantum dots CdS is deposited on substrates (glass) using (MW-CBD) method. The solution containing (0.01M) in deionized water (DW) of $\left[\mathrm{Cd}\left(\mathrm{NO}_{3}\right)_{2}\right]$ (purity (98\%), Sigma Aldrich), and $(0.01 \mathrm{M})$ in DW of $\left[\mathrm{CH}_{4} \mathrm{~N}_{2} \mathrm{~S}\right]($ purity $(99 \%)$, Sigma Aldrich), are given a $\mathrm{Cd}^{+2}, \mathrm{~S}^{-2}$ ions source. [ $\mathrm{NH}_{4} \mathrm{CH}_{3} \mathrm{COO}$ ] (purity (98\%), HoneyWell), with (1M) in DW to control reaction rate, a buffer solution is added [24]. Ammonia solution (purity (98\%), HoneyWell), is added to adjust the $\mathrm{pH}$ of the solution to (10). After stirred the solution for $(5 \mathrm{~min})$, the solution in the beaker is transferred to a microwave oven with $\left(2.45 \mathrm{GHz}\right.$ frequency, LG, Korea) and the temperature is fixed at $\left(70^{\circ} \mathrm{C}\right)$ and the duration time is $(45 \mathrm{~min})$. Finally, washed the samples by DW after completing the preparation to take off any impurities. The yellowish layer indicates the preparation $\mathrm{CdS}$ nanoparticles. The $\mathrm{CdS}$ nanoparticles thin films obtained were free of cracks and high adhesion on substrates.

Structural properties studied using X-ray diffraction (XRD) (X'Pert PRO, Philips Company, Holland). The composition of CdSQDs films was studied by energy dispersion X-ray spectroscopy (EDX) (NOVA NanoSEM, FEI Company, USA). Morphology studded by (FE-SEM) (NOVA NanoSEM, FEI Company, USA) operating at $10.0 \mathrm{kV}$. Optical measurements at RT using (UV-Vis. SHIMADZU Company, 1800, Japan) spectrophotometer and photoluminescence (PL) spectrum was recorded using a (SHIMADZU Company, RF-5301, Japan).

\section{The reaction of preparation CdS nanoparticles}

The reaction below refers to the production of ammonium ions and hydroxide as a result of adding an ammonia solution to the water:

$\mathrm{NH}_{3}+\mathrm{H}_{2} \mathrm{O} \leftrightarrow \mathrm{NH}_{4}^{+}+\mathrm{OH}^{-}$

Dissolution $\left[\mathrm{Cd}\left(\mathrm{NO}_{3}\right)_{2}\right]$ in DW leads to provide free $\left(\mathrm{Cd}^{+2}\right)$ ions, $\left(\mathrm{Cd}^{+2}\right)$ ions react with the $\left(\mathrm{OH}^{-}\right)$produce $\left[\mathrm{Cd}(\mathrm{OH})_{2}\right]$. Finally, react with $\left(\mathrm{NH}_{\mathrm{a}}\right)$ obtained $\left[\mathrm{Cd}\left(\mathrm{NH}_{3}\right)_{4}\right]^{+2}$. As shown in the interaction below [2].

$$
\begin{gathered}
\mathrm{Cd}^{+2}+2 \mathrm{OH}^{-} \leftrightarrow \mathrm{Cd}(\mathrm{OH})_{2} \\
\mathrm{Cd}(\mathrm{OH})_{2}+4 \mathrm{NH}_{\mathrm{a}} \leftrightarrow\left[\mathrm{Cd}\left(\mathrm{NH}_{3}\right)_{4}\right]^{+2}+2 \mathrm{OH}^{-}
\end{gathered}
$$

Adding $\left(\mathrm{CH}_{4} \mathrm{~N}_{2} \mathrm{~S}\right)$ leads to the production of $\mathrm{S}^{-2}$ ions, shown equations below:

$$
\begin{gathered}
\left(\mathrm{NH}_{2}\right)_{2} \mathrm{CS}+\mathrm{OH}^{-} \leftrightarrow \mathrm{SH}^{-}+\mathrm{CN}_{2} \mathrm{H}_{2}+\mathrm{H}_{2} \mathrm{O} \\
\mathrm{SH}^{-}+\mathrm{OH}^{-} \leftrightarrow \mathrm{S}^{-2}+\mathrm{H}_{2} \mathrm{O}
\end{gathered}
$$

Finally, CdS nanoparticles obtained using reaction $\left[\mathrm{Cd}\left(\mathrm{NH}_{3}\right)_{4}\right]^{2+}$ complex with $\mathrm{S}^{-2}$ ions as shown below:

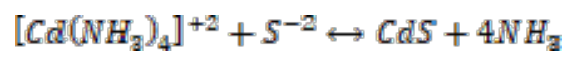


The concentration of $\mathrm{OH}^{-}$ions is very dependent on the $\mathrm{pH}$ value that in turn very affected by the temperature. Furthermore, the stability constant of a complex is temperature-dependent where increasing temperature led to increasing dissociation of the complex. Therefore, the temperature of the reaction is a very important parameter in the (MW-CBD) method [20].

\section{Results and Discussion \\ Structural analysis}

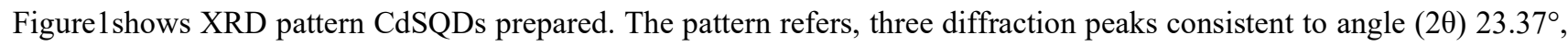
$26.66^{\circ}$ and $29.05^{\circ}$ for the sample. This peaks positions consistent with planes of $\mathrm{h}(100), \mathrm{h}(002)$ or c (111) and h (101) which refers to a Zincblend a hexagonal structure, correspond with (ICCD-PDF4 No.00-001-0647 and 00-001-0780) [2]. Other peaks consistent to angle (20) $39.03^{\circ}, 44.20^{\circ}, 47.37^{\circ}$ and $51.78^{\circ}$ consistent to planes $\mathrm{h}(102), \mathrm{h}(110)$ or c (220), $\mathrm{h}$ (103) and $\mathrm{h}(112)[25,26]$. In general, it is difficult to determine whether the primary lattice phase of a compound CdS is hexagonal or cubic due to convergence diffraction peaks. However, the plans (100), (101), (103) and (112) if the primary lattice phase is hexagonal. The grain size CdS nanoparticles were estimated by Scherer's relationship [27].

$$
G \cdot S=\frac{0.9 \lambda}{\beta \cos \theta}
$$

Where (G.S) grain size, $\lambda$ wavelength, $\beta$ FWHM (radians), and $\theta$ diffraction angle. The grain size average was CdS nanoparticles $(12.23 \mathrm{~nm})$.

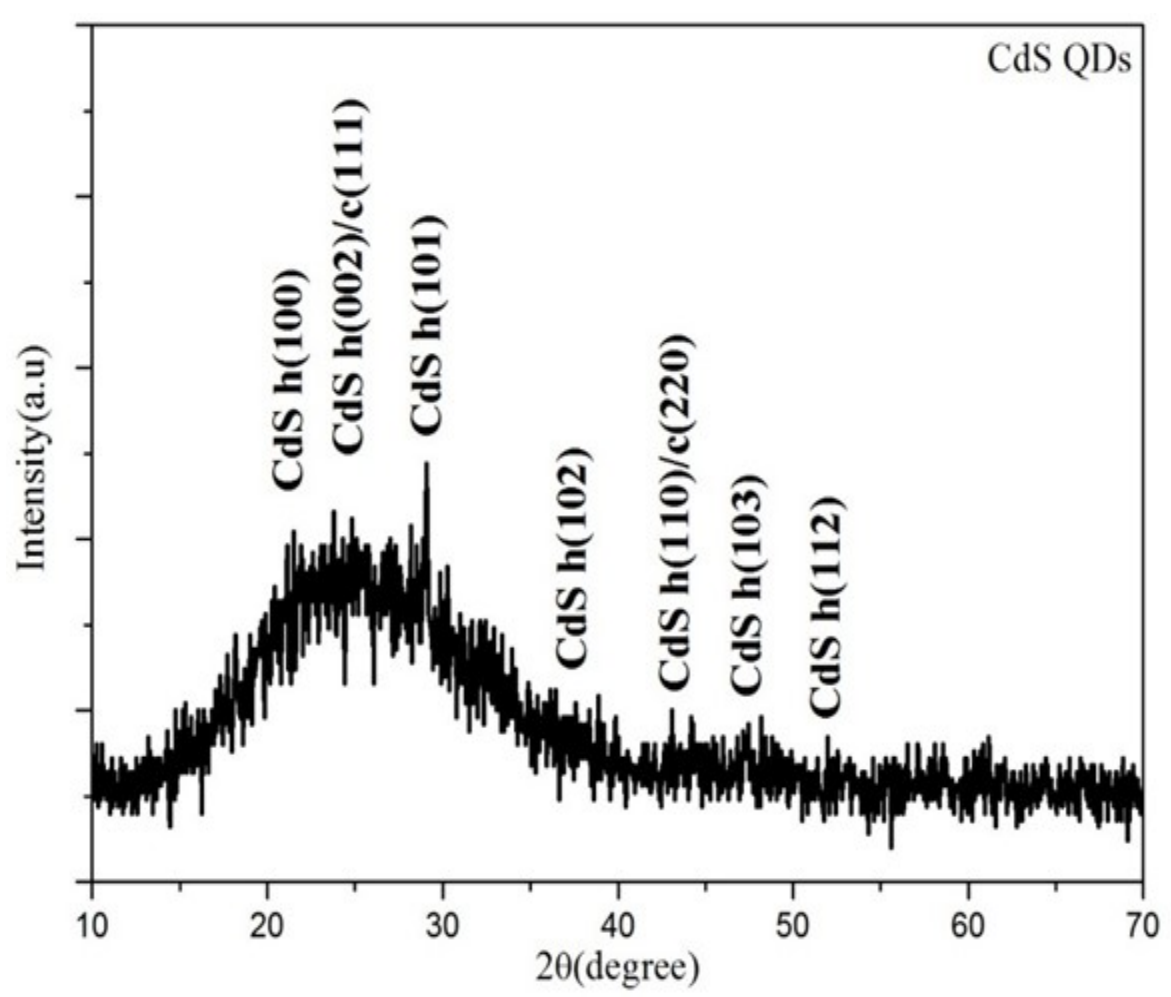

Figure 1 XRD of CdSQDs thin film. 


\section{Morphological and EDX characterization}

Morphological characteristics of CdS quantum dots were analyzed using (FE-SEM) captured at different magnifications as shown in Figure 2 ( $a$ and $b$ ), which refers to formation of quantum dots. Particles form larger groups [2]. It showed that the particles exhibited spherical granules like structure [28]. It should be noted that generally, CdS layers have good adhesion with the surface of the substrate. The thickness of thin-film CdSQDs was measured using field emission scanning electron microscopy (cross-section) shown in Figure 2 (c). The thickness of the sample was ranged (37.77nm). In addition, Figure 2 (d) illustrates the diameters average distribution of the CdSQDs sample on the substrate. it should be noted that in the manufacture of optical-electronic devices, especially solar cells, the porous structure materials are the best to use. The results of (EDX) are analyzed to confirm the purity of (CdS). (EDX) of CdS quantum dots is shown in Figure 3 and data in Table 1. The results confirm purity present in the sample and from this data, the cadmium to sulfur ratio was found (1.15).

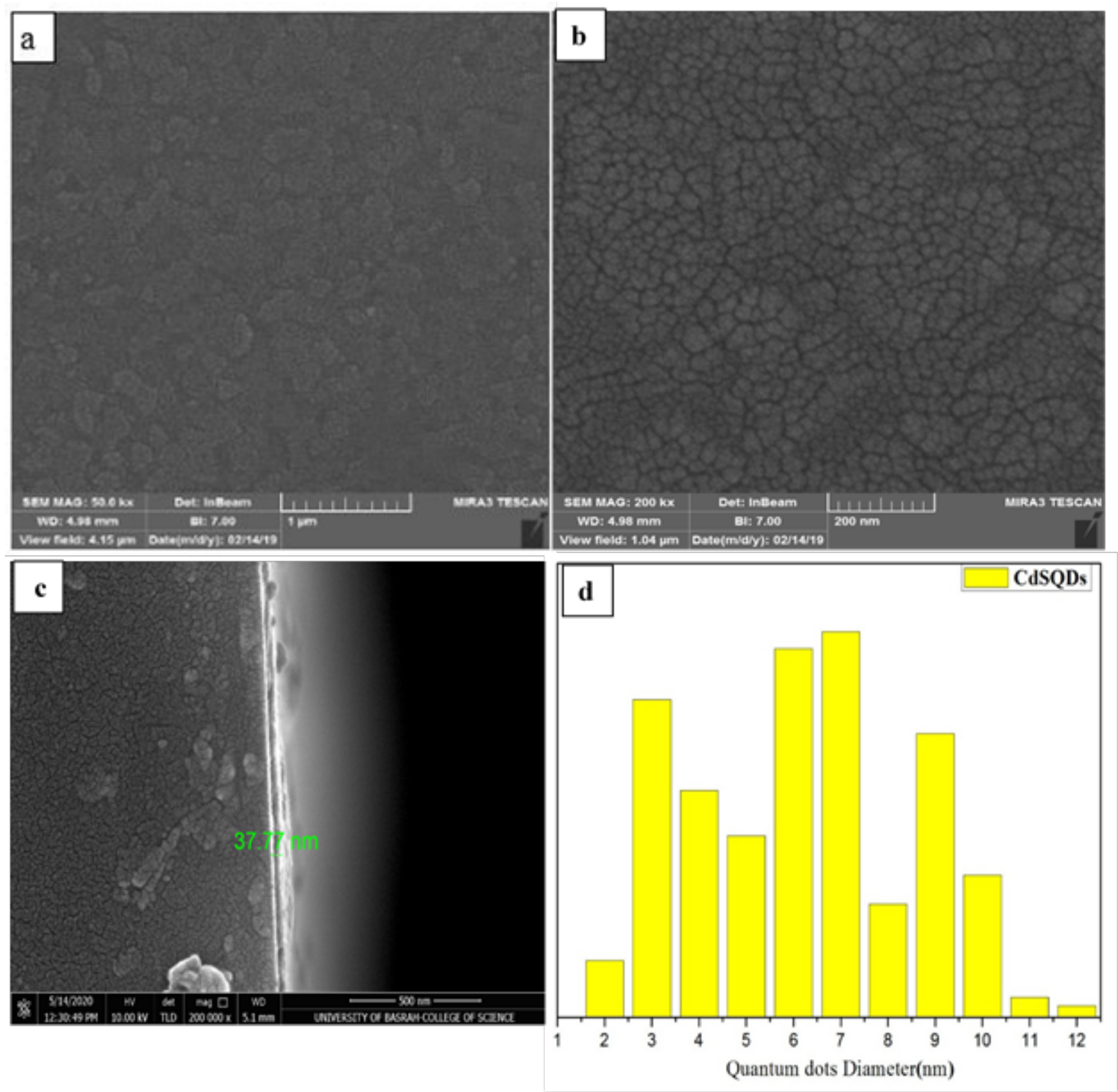

Figure 2 ( $a$ and b) FE-SEM images of CdS quantum dots thin film at different magnifications, (c) cross-section images of CdS quantum dots thin film, (d) diameters average distribution. 


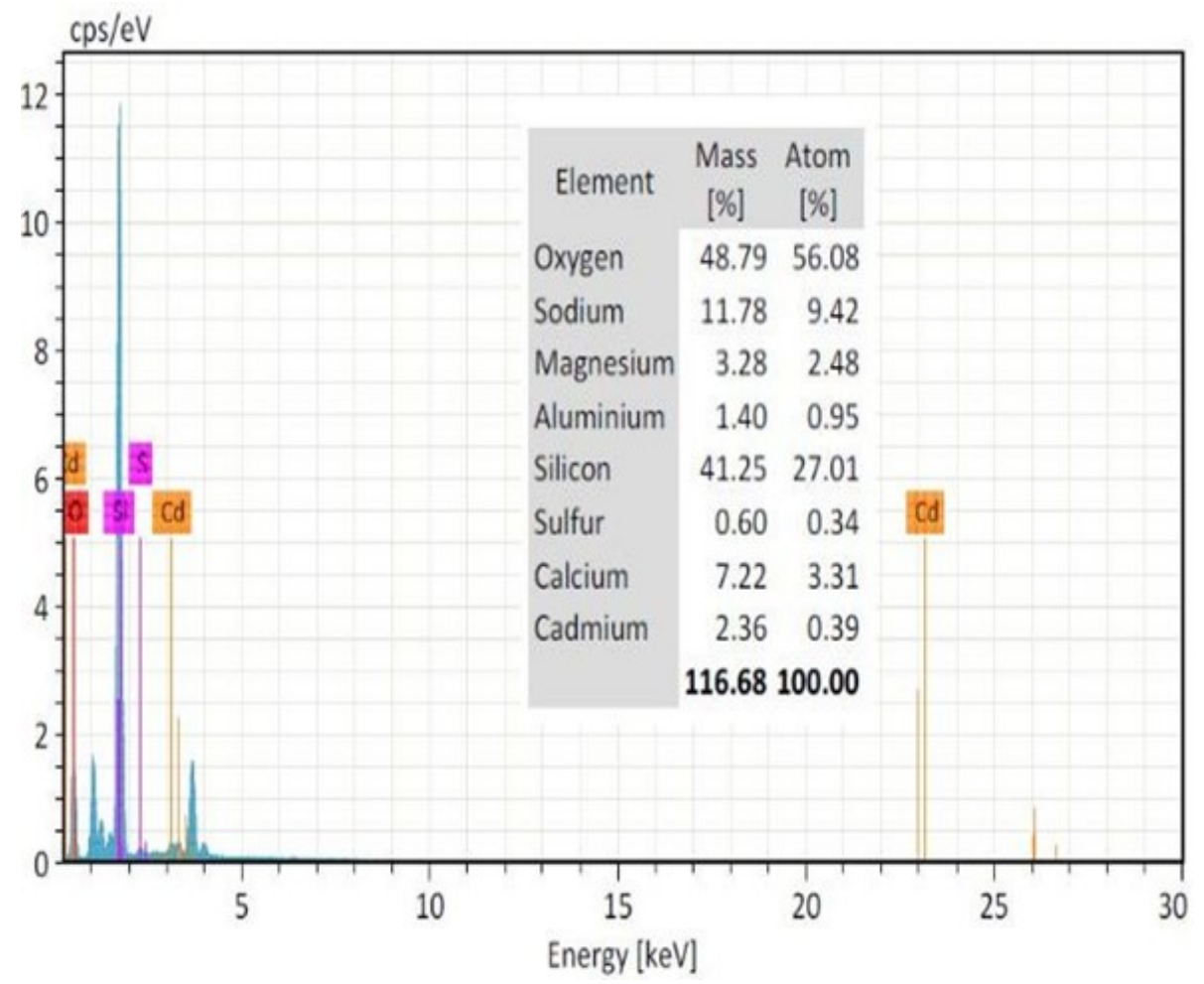

Figure 3 EDX of CdS quantum dots thin film prepared on a glass substrate

\section{Optical properties}

\section{Optical absorption}

The most dramatic property of semiconductor nanoparticles is the size evolution of optical absorption spectra. Hence UVvisible absorption spectroscopy is an efficient technique to monitor the optical properties of quantum-sized particles. The bulk bandgap of CdS is $2.42 \mathrm{eV}$ [29]. UV-visible absorption studied at RT within the wavelength of 300-800 nm. The UV-visible absorption of CdSQDs sample prepared is shown in Figure 4. The maximum absorption for CdS as a bulk material is around $460 \mathrm{~nm}$. This result is the corresponding value reported [3]. Absorption of CdS changes with the particle size. A shift of $460 \mathrm{~nm}$ absorption compared with the characteristic absorption of bulk CdS may be due to quantum confinement effects. In our study $(\mathrm{Eg})$ is estimated by the Tauc relationship [30]. The absorption coefficient ( $\alpha$ ) was estimated by the relationship [31].

$$
\alpha=\frac{2 \cdot 303}{d} A
$$

Where (d) thin-film thickness and $\left({ }^{A}\right)$ absorption. Optical energy bandgap (Eg) was estimated by relationship [32].

$$
\alpha h v=B(h v-E g)^{1 / 2}
$$

The $(\mathrm{Eg})$ value determined from Figure 5 is $(2.6 \mathrm{eV})$, bandgap value was higher than the bulk CdS band gap $(2.42 \mathrm{eV})$ due to the confinement effect due to small particle size. Particle radius (R) was estimated by relationship [2]:

$$
\Delta E_{g}=\frac{\hbar^{2} \pi^{2}}{2 R^{2}}\left(\frac{1}{m_{e}^{*}}+\frac{1}{m_{h}^{*}}\right)-\frac{1 \cdot 8 e^{2}}{4 \pi \varepsilon \varepsilon_{\circ} R}
$$

Where $\left(m_{e}^{*}\right)$ and $\left(m_{h}^{*}\right)$ effective masses electron and hole, (h) Planck's constant, (e) electron charge, $\left({ }^{\varepsilon \approx}\right)$ permittivity of free space $(8.854 \times 10-12 \mathrm{C} 2 \mathrm{~N}-1 \mathrm{~m}-2),\left({ }^{\varepsilon}\right)$ relative permittivity. 
Particle size (P.S) of CdS (P·S =2R), estimated size CdS $7.5 \mathrm{~nm}$ (Table 1) which indicate quantum size effect. It can be observed the results estimated size nanoparticles CdS prepared were close to all methods used. The observed result of (XRD) estimated particle size was different, because (XRD) measures size particle group (grain size) corresponding to the diffraction peaks using the Bragg relationship. Therefore, the grain size obtained from Scherrer's relationship, an estimate of the average unit cell size [2].

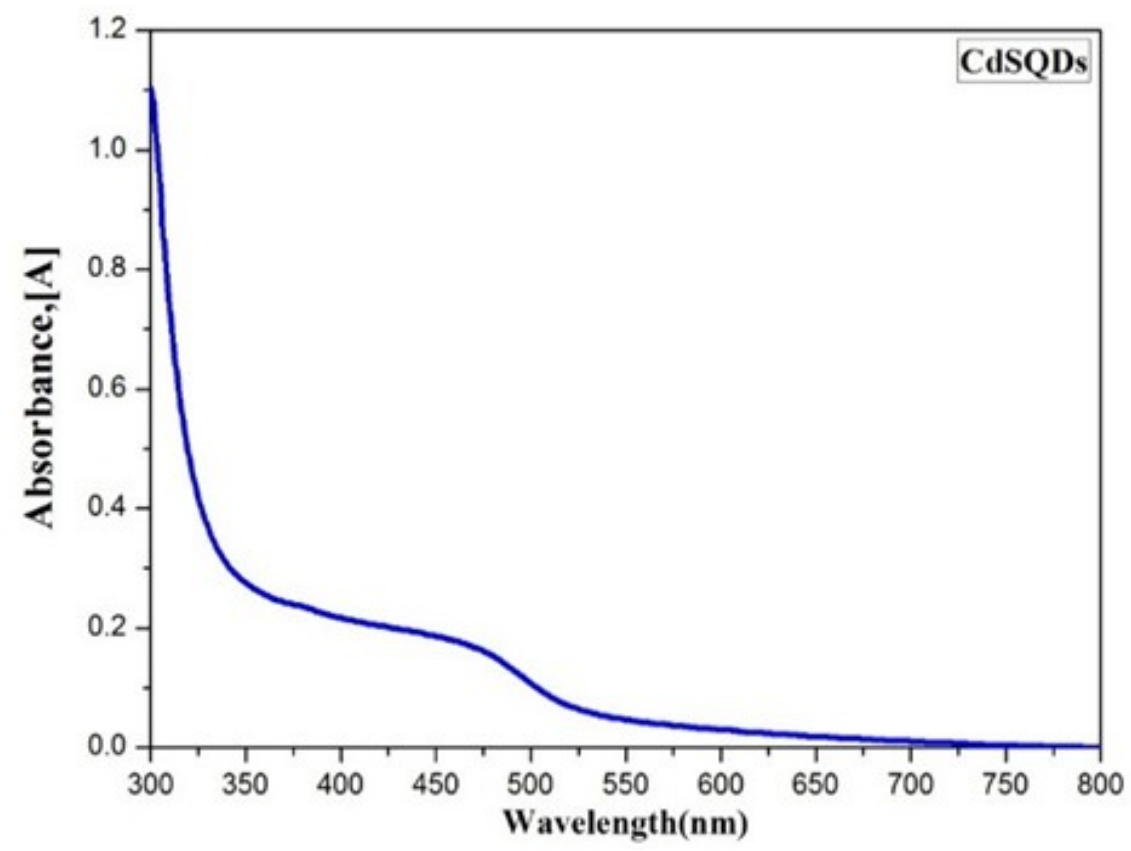

Figure 4 Absorption spectrum for CdS quantum dots.

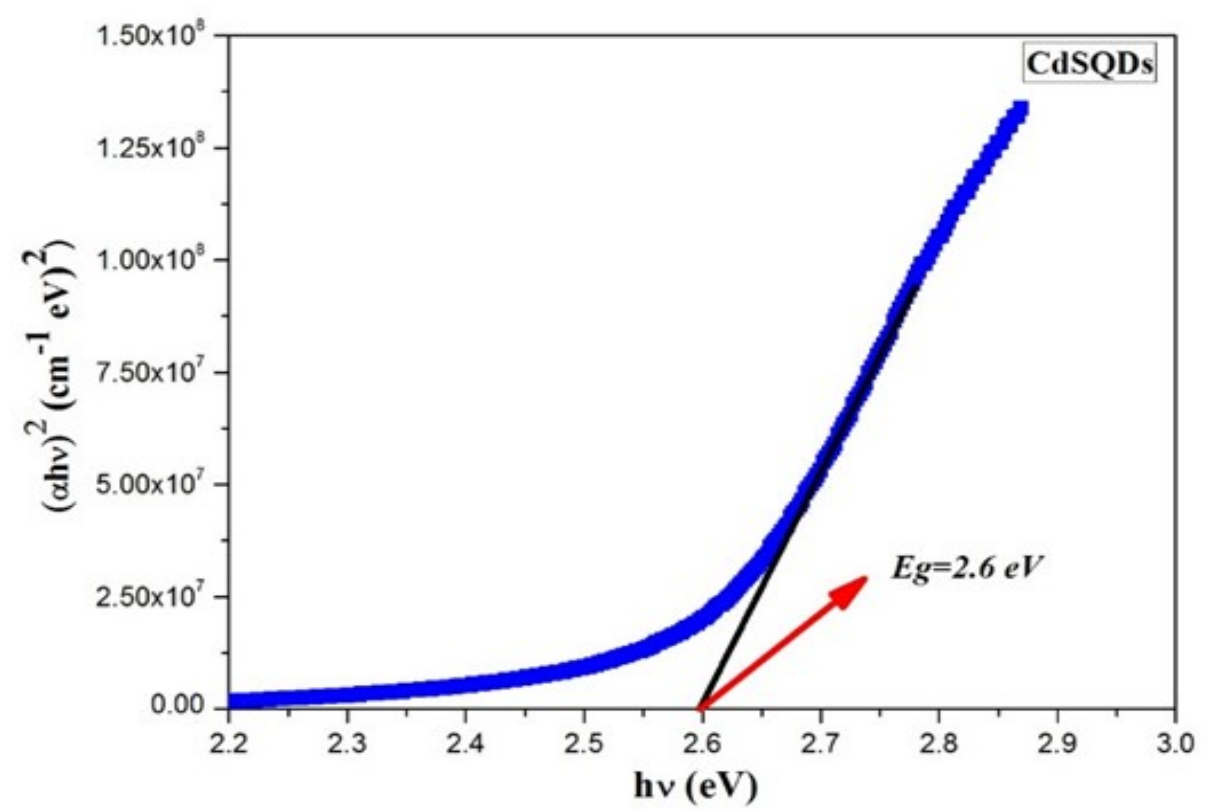

Figure 5 Estimated bandgap from the optical absorption spectrum for CdS quantum dots. 
Table 1 Eg and CdS particle size (P.S).

\begin{tabular}{lllll}
\hline \multirow{2}{*}{ Sample } & \multirow{2}{*}{$\boldsymbol{E} g(\mathrm{eV})$} & \multicolumn{3}{c}{ P.S average $(\mathrm{nm})$} \\
\cline { 3 - 5 } & & XRD(G.S) & FE-SEM & Mass model \\
\hline $\mathrm{CdS}$ & 2.6 & 12.23 & 7 & 7.5 \\
\hline
\end{tabular}

The photoluminescence (PL) spectrum of CdS quantum dots, refers to light emission due to the return electrons from the excited state to the ground state after an incident with a monochromatic wavelength on it. Most, light incident onto CdS quantum dots is absorbed by atoms in the outside layers of nanoparticles, due to the low intensity of the lamp used. The result of (PL) spectra should refer to available energy states at the outside layers of CdS quantum dots. Figure 6 shows the room temperature photoluminescence (PL) spectrum of the quantum dots $\mathrm{CdS}$ at $220 \mathrm{~nm}$ excitation wavelength. The emission spectrum shows four important bands. Its band at $440 \mathrm{~nm}$ (highest peak) is the band-edge photoluminescence peak for CdS quantum dots [33]. The second band at (470) nm refers (Eg) the transition of CdS quantum dots. The third band at (480-525) $\mathrm{nm}$ refers to the $(\mathrm{Eg})$ transition of bulk $\mathrm{CdS}$, band at $658 \mathrm{~nm}$ refers to electron transition of defects in CdS structure. [34]. The (FWHM) of PL is 10nm, it reveals that the narrow size distribution of nanoparticles [5]. Crystalline defects or impurities may be due to a high reaction temperature or solution $\mathrm{pH}$ values. The blue shift and high peak intensity observed in the figure indicate quantization in CdS nanoparticles particles [35,36].

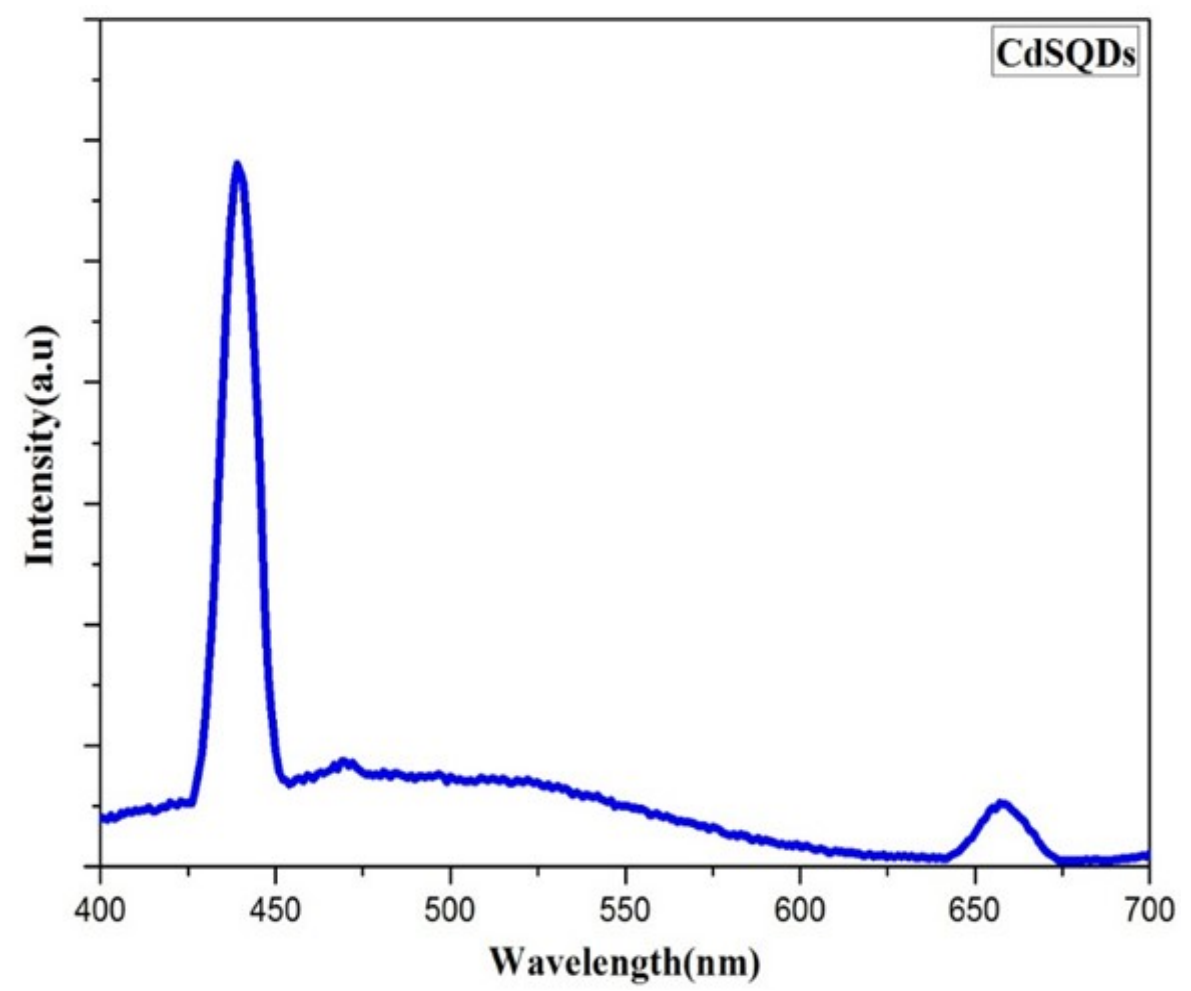

Figure 6 Photoluminescence (PL) spectrum of CdS quantum dots.

\section{Conclusion}

In the present work, the synthesis of CdS nanoparticles (Quantum Dots) thin film at size average (7) nm via (MW-CBD) on substrates (glass) successfully. The presented route can easily fabricate CdS nanoparticles with small dimensions in short periods and at $\left(70^{\circ} \mathrm{C}\right)$ temperature. CdS quantum dots have been analyzed by XRD, FE-SEM, EDX, UV-Vis, and 
PL. The result of XRD studies, illustrated all XRD peaks corresponded to CdS quantum dots. Great homogeneity and fewer pinholes and cracks of CdSQDs thin film prepared are illustrated (FE-ESM) results. The results of (EDX) are analyzed confirm the purity of (CdS), the results confirm purity present in the sample and from this data, the cadmium to sulfur ratio was found (1.15). The optical band gap (Eg) of CdSQD was determined by using UV-Vis spectra it was found of $(2.6 \mathrm{eV})$. The $(E g)$ value was higher than the bulk CdS band gap due to the confinement effect due to small particle size. In addition, the blue shift and high peak intensity observed in the PL spectrum indicate quantization in CdS nanoparticles particles. From the results obtained, it can be concluded the CdSQDs thin films prepared can be used in optoelectronic applications. The use of (MW-CBD) technique to prepare semiconductor nanoparticles is an appropriate and effective option in terms of accelerating the reaction and homogeneous heat distribution.

\section{References}

[1] Chen, Y., Pepin, A, Nanofabrication: Convention and nonconventional methods, Electrophoresis, 2001, $187-207$.

[2] Mahdi, M.A. Hassan, Z, Ng ,S.S, Hassan, J.J, Mohd Bakhori, S.K, Structural and optical properties of nanocrystalline CdS thin films prepared using microwave-assisted chemical bath deposition, Thin Solid Films, 2012, 3477-3484.

[3] De la cruz terrazas, E. C. R, Ambrosio lazaro, C, Mota gonzalez, M.L, Luque, P.A, Castillo, S. J, Carrillo-Castillo, A, A simple method for the synthesis of CdS nanoparticles using a novel surfactant Chalcogenide Letters, 2015,147 153.

[4] Zhu, J, Zhou, M, Xu, J, Liao, X, Preparation of CdS and ZnS nanoparticles using microwave irradiation, Materials Letters, 2001, 25-29.

[5] Srinivasa rao, B, Rajesh kumar, B, Rajagopal reddy, Subba rao, V.T, Preparation and characterization of CdS nanoparticles by chemical co-precipitation technique, Chalcogenide Letters, 2011, 177 - 185.

[6] Filipponi, L. and Sutherland, D. Nanotechnologies. Luxembourg: Europen Union, 2013.

[7] A. Mishra, S. Saha, Fabrication and comparison of Heterojunction solar cells from CdS/PbS nanoparticles and $\mathrm{CdS} / \mathrm{PbS}$ bulk, Nano Express, 2020, 1-9.

[8] Y. Hu, B. Wang, J. Zhang, T. Wang, R. Liu, J. Zhang, X. Wang, H. Wang, Synthesis and photoelectrochemical response of $\mathrm{CdS}$ quantum dot-sensitized $\mathrm{TiO}_{2}$ nanorod array photoelectrode, Nanoscale Research Letters, 2013 , 1-5.

[9] Ali N, Iqbal MA, Hussain ST, Waris M, Munair SA, Optoelectronic properties of cadmium sulfide thin films deposited by thermal evaporation Technique, Key Engineering Materials, 2012, 510-511.

[10] GM, W, ZQ, Z, YY, Z, Cao, Y, Zhou, Y, GJ, X, Study of transmittance of CdS thin films prepared by spray pyrolysis, Applied Mechanics and Materials, 2012, 130-134.

[11] Zhou LM, Hu XF, Wu SM, Effects of $\mathrm{pH}$ value on performance of CdS films with chemical bath deposition, Advanced Materials Research, 2012, 557-559.

[12] Senthamilselvi, V, Saravanakumar, K, Begum, J, Anandhi, R, Ravichandran, A, Sakthivel, B, Photovoltaic properties of nanocrystalline CdS films deposited by SILAR and CBD techniques comparative study. Mater Sci Mater Electron, 2012, 302-308.

[13] Farooq, U, Naz, F, Phul, R, Pandit, N.A, Jain, S.T, Ahmad, T, Development of Heterostructures Ferroelectric $\mathrm{SrZrO}_{3} / \mathrm{CdS}$ Photocatalyst with Enhanced Surface Area and Photocatalytic Activity, Journal of Nanoscience and Nanotechnology, 2020, 3770-3779.

[14] Ekinci, A, Horoz, S, Şahin, O, Effect of Ce doping on the characteristic properties of CdS nanoparticles, Chalcogenide Letters, 2020, 263-268.

[15] Ramazanov, M.A, Hajiyeva, F.V, Babayev, Y.A, Valadova, G.V, Nuriyeva, S.G, Shirinova, H.A, Synthesis and optical properties of PVC-CdS based nanocomposites, Journal of Elastomers \& Plastics, 2020, 159-166.

[16] Sheng, C.K, Alrababah, Y.M, The Role of pH on Infrared Spectral, Structural and Morphological Properties of Roomtemperature Precipitated CdS Nanoparticles, Journal of Nano and electronic physics, 2020, 1-4.

[17] Dasa, H, Boruahb, P.K, Dattaa, P, Microwave Assisted Synthesis of CdS \& CdS/ZnS Core-Shell Nanoparticles and Their Characterization, International Journal of Advanced Research in Physical Science (IJARPS), 2015, 18-23.

[18] Murray, C.B, Norris, D.J, Bawendi, M.G, Synthesis and characterization of nearly monodisperse CdE (E $=$ sulfur, selenium, tellurium) semiconductor nanocrystalline, J.Am.Chem. Soc.,1993), 8706-8715.

[19] Ayodhya, D, Venkatesham, M, Kumari, A.S, Mangatayaru, K.G, Veerabhadram, G, Synthesis, Characterization of $\mathrm{ZnS}$ nanoparticles by Coprecipitation method using various capping agents - Photocatalytic activity and Kinetic study, Journal of Applied Chemistry, 2013, 1-9.

[20] Pinilla, M.A, Moreno, L.C, Guzman, G.G, Optical and morphological properties of CdS nanoparticles thin films deposited by CBD process, Chalcogenide Letters, 2011, 601-609.

[21] Panda, A.B, Glaspell, G, Samy, M, Microwave synthesis of highly aligned ultra-narrow semiconductor rods and 
wires, J. Am. Chem. Soc., 2006, 2790.

[22] Choubey, S.K, Tiwary, K.P., Microwave assisted synthesis of CdS nanoparticles for structural and optical Characterization, International Journal of Innovative Research in Science Engineering and Technology, 2014, 1067010674.

[23] Entezari, M.H., Ghows, N., Micro-emulsion under ultrasound facilitates the fast synthesis of quantum dots of CdS at low temperature, Ultrason. Sonochem., 2010, 127-134.

[24] Husham, M, Hassan, Z, Mahdi, M.A, Selman, A. M, Nanocrystalline CdS thin films growth on silicon substrate via microwave-assisted chemical bath deposition synthesis and characterization, International Journal of Technical Research and Applications, 2014, 11-13.

[25] Devenderan, P, Alagesan, T, Panding, K, Single Pot Microwave Synthesis of CdS Nanoparticles in Ionic Liquid and Their Photocatalytic Application, International Conference on Nanoscience \& Nanotechnology, 2013, 79-82.

[26] Ibrahim, A.O, Suhail, M. A, Synthesis CdS nanocrystal by using nanoparticle in chemical method, Proceeding of 3rd scientific conference, 2009, 2175- 2180.

[27] Soltani, N, Saion, E, Hussein, M.Z, Yunus, R.B, Navaseri, M, Characterization of CdS Nanoparticles Synthesized using Microwave assisted Polyol Method, Advanced Materials Research, 2013, 122-127.

[28] Ashok, C.H, Venkateswara, K, Shilpa, C.H, Rajendar, V, Structural Properties of CdS Nanoparticles for Solar Cell Applications, Int. J. Pure Appl. Sci. Technol., 2014, 8-12

[29] Al-Taay, H. F, Preparation and Characterization of Chemical Bath Deposition synthesis CdS Nanocrystalline Thin Films Iraqi Journal of Science, 2017, 454-461.

[30] Holloway, T, Mundle, R, Dondapati, H, Bahoura, M, Pradhana, A. K, Al-doped ZnO aligned nanorod arrays: Significant implications for optic and opto-electronic Applications, Center for Materials Research.

[31] Akhiruddin, Sugianto, Irmansyah, The Influence of Hydrothermal Duration on Structures and Optical Properties of ZnO Nanoparticles, Journal of Materials Physics and Chemistry, 2014, 34-37.

[32] Soltani, N, Salon, E, Erfani, M, Bahrami, A, Navaseri, M, Rezabe, K, Zobir, M, Facile synthesis of ZnS/CdS and $\mathrm{CdS} / \mathrm{ZnS}$ core-shell nanoparticles using microwave irradiation and their optical properties, Chalcogenide Letters, 2012, 379 - 387

[33] Martinsson, L, "Low-temperature synthesis of CdS nanocrystals in aliphatic alcohols", thesis, Uppsala University, (2010.)

[34] Carlos, A, Castaneda, R, Paola, M, Romero, M, Alonso, C.M, Hailin, H, Microwave Synthesized Monodisperse CdS Spheres of Different Size and Color for Solar Cell Applications, Journal of Nanomaterials, 2015, 1-10.

[35] Chaudhuri, R. G, Paria, S, Core/shell nanoparticles: classes, properties, synthesis mechanisms, characterization, and applications, Chemical Reviews, 2012, 2373-2433.

[36] Shankar, H.S, Dhote, D, Vidhale, M, A facile route for preparation of CdS nanoparticle, Sci. Revs. Chem. Commun., 2012, 427-431. 